\title{
SAP VALENCIA 25 DE MAYO 2020. LA IGNORANCIA DEL RECONOCIMIENTO AUTOMÁTICO DE RESOLUCIONES EN MATERIA DE DERECHO DE ALIMENTOS EUROPEO. UNA RESOLUCIÓN PARALELA
}

\author{
(DECISION OF THE PROVINCIAL COURT OF VALENCIA \\ OF 25 MAY 2020) THE IGNORANCE OF THE AUTOMATIC \\ RECOGNITION OF RESOLUSIONS IN EUROPEAN \\ MAINTENANCE RIGHTS. A PARALLEL RESOLUTION \\ OF THE CASE
}

\author{
Silvia Recuenco PÉRez \\ Abogada. Profesora Asociada de Derecho Internacional Privado \\ Universidad Carlos III de Madrid
}

Recibido: 12.11.2020 / Aceptado: 11.12.2020

DOI: https://doi.org/10.20318/cdt.2021.6014

\begin{abstract}
Resumen: El reconocimiento y ejecución de resoluciones en materia de familia exige la necesidad de individualizar el Reglamento europeo aplicable según el tipo de materia. Con relación a las obligaciones alimenticias, el Reglamento 4/2009 dispone que tendrán fuerza ejecutiva de pleno derecho y sin posibilidad de oponer motivos de rechazo al reconocimiento, siempre que el Estado de origen y el requerido estén vinculados por el Protocolo de la Haya de 2007. La sentencia objeto de comentario lo ignora y no reconoce una sentencia dictada en Rumania con anterioridad a otra española entre las mismas partes, objeto y causa, vulnerando entre otras cosas, el principio esencial a la libre circulación de resoluciones europeas e imponiendo la resolución española.

Palabras clave: cosa juzgada, reconocimiento y ejecución de resoluciones extranjeras en la unión europea, derecho de alimentos, libre circulación de resoluciones europeas, derecho internacional privado

Abstract: The recognition and enforcement of decisions in family matters need to individualize what European Regulation should be applied according to the type of matter. With regard to maintenance obligations, Regulation 4/2009 provides that they will have full right enforceability without the possibility of opposing reasons for rejection of recognition, provided that the State of origin and the requested State are bound by the Hague Protocol of 2007. The mentioned sentence ignores it and does not recognize a sentence handed down in Romania before another one in Spain between the same parties, purpose and cause, violating, among other things, the essential principle of the free circulation of European resolutions.
\end{abstract}

Keywords: res judicata, recognition and enforcement of foreign decisions in the European Union, maintenance law, free movement of resolutions, international Private Law.

Sumario: I. Antecedentes II. Resolución por la Audiencia Provincial. III. Cuestiones jurídicas del caso IV. Coexistencia de diferentes instrumentos internacionales aplicables a la validez extraterritorial de decisiones europeas dentro del derecho de familia. V. Cosa juzgada internacional, ley aplicable y modificación de medidas: un "totum revolutum". VI. Conclusión. 


\section{Antecedentes}

1. El Juzgado de Primera Instancia español dictó sentencia de fecha 14 de enero de 2019, en rebeldía del demandado, en la que estima la disolución del matrimonio celebrado entre dos cónyuges rumanos, el 25 de enero de 2007 en Rumania. Establece patria potestad compartida y custodia de los dos hijos menores a favor de la madre, sin visitas para el padre. También regula una pensión de alimentos por importe 200 euros por hijo, sin límite temporal alguno.

2. La sentencia de instancia fue recurrida por el esposo demandado, alegando como motivo principal la excepción procesal de cosa juzgada internacional. En su recurso, solicita el reconocimiento incidental de una sentencia dictada por el Juzgado de Botosani (Rumania) en fecha 9 de noviembre de 2018, es decir, dos meses y seis días antes que la española, dictada en el seno de un procedimiento entre las mismas partes, con el mismo objeto y misma causa, solicitando que se estime la excepción procesal de cosa juzgada y se revoque la sentencia dictada en primera instancia por el juzgado español. ${ }^{1}$

3. La sentencia del Juzgado de Botosani (Rumani) fue dictada en rebeldía voluntaria de la esposa y en su fallo se acuerda, además de la disolución del matrimonio, la autoridad parental de los menores, ejercitada por ambos progenitores, un horario de relaciones personales y la obligación del padre de pagar alimentos a favor de sus dos hijos por importe de 190 lei al mes por cada hijo, hasta su mayoría de edad. ${ }^{2}$

4. El reconocimiento incidental de la sentencia dictada por el Juzgado de Botosani, se solicita con base en el art 21.4 del Reglamento (CE) n ${ }^{\circ} 2201 / 2003^{3}$ del Consejo, de 27 de noviembre, relativo a la competencia, el reconocimiento y la ejecución de resoluciones en materia matrimonial y de responsabilidad parental. No consta, sin embargo, que el recurrente invocara el Reglamento (CE) 4/20094 del Consejo, de 18 de diciembre de 2008, norma que regula el sistema de reconocimiento y ejecución de las obligaciones alimenticias, con independencia, como se verá más adelante, de su reconocimiento sea automático según en qué situaciones.

5. La parte apelada (esposa) se opone al reconocimiento respecto del divorcio y responsabilidad parental y alega, como motivo de rechazo, que desconocía el procedimiento que se tramitaba en $\mathrm{Ru}$ mania al haber sido indebidamente notificada, lo que le causaba indefensión. También se opone, expresamente, al reconocimiento del pronunciamiento sobre derecho de alimentos. En este caso argumenta que su reconocimiento implicaría una vulneración del derecho de los hijos a percibir una pensión que

\footnotetext{
${ }^{1}$ SAP Valencia 25 mayo 2020, [ECLI: ES:APV:2020:1519].La sentencia comentada, literalmente, establece en su fundamento jurídico primero, párrafo segundo, que "El apelante pretende el reconocimiento incidental de sentencia civil $n^{\circ} 4794$ que se dictó por el Juzgado de Botosani (Rumania) en el procedimiento de divorcio (expediente 6625/193/2015) y, en consecuencia, que se considere cosa juzgada el pronunciamiento judicial de divorcio y las medidas que fueron dispuestas por el Tribunal rumano y se revoque la sentencia apelada, dictada en su rebeldía" Este párrafo parece indicar que el apelante solicitó el reconocimiento incidental de la totalidad de la resolución. Aunque se desconoce si la argumentación jurídica era correcta o no, de la literalidad de la sentencia comentada puede deducirse que incluía, también, la solicitud de reconocimiento del pronunciamiento sobre obligación alimenticia al hablar de "medidas" en general sin establecer diferencias entre medidas personales y patrimoniales sobre los menores.

${ }^{2}$ Aunque la resolución objeto de comentario nada menciona sobre la ley aplicable en la sentencia dictada por el tribunal rumano, ni respecto de la responsabilidad parental ni sobre la pensión de alimentos, de la literalidad de esta podríamos deducir que se aplicó derecho de Rumania. Así parece desprenderse de los términos jurídicos que se utilizan para designar conceptos como "autoridad parental" u "horario de relaciones personales".

${ }^{3}$ Reglamento (CE) n ${ }^{\circ}$ 2201/2003 del Consejo, de 27 de noviembre, relativo a la competencia, el reconocimiento y la ejecución de resoluciones en materia matrimonial y de responsabilidad parental (Reglamento Bruselas II bis) DOUE $\mathrm{n}^{\circ} 338$, de 23 de diciembre de 2003. Este reglamento será sustituido por el Reglamento (UE) 2019/1111, de 25 de junio de 2019, sobre reconocimiento y ejecución de resoluciones en materia matrimonial y de responsabilidad parental, así como sobre la sustracción internacional de menores (DOUE L 178, de 2 de junio de 2019) siendo de aplicación la mayoría de sus preceptos el 1 de agosto de 2022.

${ }^{4}$ Reglamento (CE) no 4/2009 del Consejo, de 18 de diciembre de 2008, relativo a la competencia, la ley aplicable, el reconocimiento y la ejecución de las resoluciones y la cooperación en materia de obligaciones de alimentos. DOUE $n^{\circ} 7$ de 19 de enero de 2009
} 
no debía finalizar con la mayoría de edad, sino con su independencia económica. Finaliza sus motivos alegando que en el caso de que se reconozca la sentencia, se mantenga el pronunciamiento español relativo a la pensión de alimentos, invocando en su razonamiento la SAP de Lérida, sección $2^{\circ}$ de 25 de noviembre de $2016^{5}$, por ser un caso similar.

\section{Solución proporcionada por la Audiencia Provincial}

6. La Audiencia Provincial de Valencia resuelve el recurso estimando parcialmente la excepción de cosa juzgada, concediendo, acertadamente, el reconocimiento incidental de los pronunciamientos de la sentencia rumana relativos a la disolución del matrimonio por divorcio y a las medidas que regulan la responsabilidad parental de los dos hijos menores. Sin embargo, no reconoce el pronunciamiento relativo a la obligación de alimentos, ignorando que, en un supuesto como éste, la regulación europea vigente les otorga fuerza ejecutiva automática, sin posibilidad de oposición al reconocimiento.

7. La fundamentación jurídica de la Sala para conceder el reconocimiento y, por tanto, estimar la excepción de cosa juzgada con relación al pronunciamiento de divorcio y responsabilidad parental, la basa en los arts. 24, 21.1 y 21.4 del Reglamento 2201/2003.

8. La denegación del reconocimiento relativo a la pensión de alimentos, lo basa por una parte en el Auto del Tribunal Supremo de 17 de septiembre de 20196, que resolvió un conflicto negativo de competencia internacional en un procedimiento de modificación de medidas y en la sentencia de la Audiencia Provincial de Lleida de 25 de noviembre de 2016, mencionada anteriormente, que alegó la parte apelada. Ambas resoluciones le llevan a entender que existe una modificación de medidas en lo relativo a la pensión de alimentos y sobre esa base, la Audiencia, sustituye -que no modifica- el pronunciamiento sobre alimentos dictado en Rumania por el de la sentencia dictada en España, justificando que la ley española es más beneficiosa para el menor por no imponer limites temporales a la pensión de alimentos.

9. Como se verá más adelante, esta es una decisión nacionalista que, desconoce o ignora la normativa europea de reconocimiento en la materia y que pretende sustituir una decisión extranjera firme y con plenos efectos de cosa juzgada por otra que, bajo su subjetividad, ve más ajustada a derecho.

\section{Cuestiones jurídicas del caso: Reconocimiento automático de ciertas resoluciones en materia de alimentos y cosa juzgada internacional}

10. Las cuestiones jurídicas objeto de análisis son sencillas, pero la resolución del asunto por la Audiencia Provincial nos lleva a reflexionar sobre las siguientes cuestiones: Validez extraterritorial de decisiones europeas en materia de derecho de familia en España, ¿Funcionan igual todos los Reglamentos europeos que regulan el reconocimiento de pronunciamientos en materia de familia? Cosa Juzgada Internacional. ¿Acierta la Audiencia al desestimar la excepción de cosa juzgada en materia de alimentos en el caso concreto? Por último, ¿Cuándo se puede modificar en España una resolución extranjera de familia?

Coexistencia de diferentes instrumentos internacionales aplicables a la validez extraterritorial de decisiones europeas dentro del derecho de familia.

11. En el contexto de una sociedad globalizada como la actual, el derecho de familia con repercusión transfronteriza es una realidad en nuestro día a día jurídico. Desde el punto de vista del derecho

\footnotetext{
${ }^{5}$ SAP Lérida 25 noviembre 2016, n 501/2016, SAL L 958/2016-ECLI:ES: APL:2016:958. Caso de reconocimiento en España de resolución dictada por un tribunal marroquí en materia de divorcio y medidas sobre los hijos menores. El caso era semejante, pero nada tienen que ver los instrumentos internacionales que se aplican al reconocimiento en uno y otro caso.

${ }^{6}$ ATS 17 septiembre 2019 [ECLI:ES:TS: 2019:9225A] [CENDOJ 28079110012019203694]
} 
internacional privado, la correcta solución jurídica de estos asuntos requiere un conocimiento preciso de sus normas en una doble vertiente: Por una parte, es necesario diferenciar el estudio y aplicación de las relativas a competencia judicial internacional, ley aplicable y reconocimiento y ejecución de resoluciones extranjeras. Por otra parte, debemos individualizar el estudio de estos tres sectores por razón de la materia concreta dentro del derecho de familia.

12. Esta precisión es importante puesto que el derecho de familia se compone de diferentes materias: disolución o nulidad de matrimonios, responsabilidad parental sobre hijos menores, derecho de obligaciones alimenticias, régimen económico matrimonial, etc. Cada una de ellas está regulada por sus propias normas de derecho internacional privado que, tanto judicatura como abogacía práctica, debemos conocer y aplicar correctamente para una adecuada solución del caso. Cuando el operador jurídico no tiene un conocimiento completo, nos encontraremos con resoluciones judiciales como la que estamos comentando. Un "quiero y no puedo" en toda regla que genera, aunque de manera inconsciente, una vulneración de los principios esenciales del derecho europeo -derecho supranacional que no puede imponerse sobre el derecho nacional- lo que puede acarrear soluciones jurídicamente incorrectas y perjudiciales para los justiciables, además de crear inseguridad jurídica.

13. Una vez localizadas las concretas normas internacionales individualizadas en función de la materia, debe completarse con un ejercicio integrador con las normas procesales internas del tribunal que conoce del asunto, lo que puede complicar la solución del caso si no se tiene claro el funcionamiento y prevalencia de unas sobre otras.

14. El litigio que resuelve la sentencia de la Audiencia Provincial de Valencia se produce entre Rumania y España por lo que centramos nuestro análisis en los instrumentos que regulan la validez extraterritorial de decisiones, únicamente, dentro de la Unión Europea. Así, el mapa de normas de derecho internacional privado en un procedimiento de divorcio o separación con hijos menores debe ser el siguiente:

\section{Reconocimiento en materia de crisis matrimoniales}

15. El reconocimiento de resoluciones en materia de divorcio se regula en los art 21 a 27 del R 2201/2003. Se trata de un sistema rápido y sencillo de reconocimiento y ejecución de resoluciones judiciales dictadas por órganos jurisdiccionales de Estados miembros parte del Reglamento. ${ }^{7}$ Este Reglamento permite solicitar el reconocimiento de resoluciones en materia de crisis matrimoniales por dos cauces: reconocimiento incidental, como es el caso analizado, y reconocimiento por homologación, el cual dotará a las resoluciones reconocidas por este procedimiento de naturaleza procesal de cosa juzgada oponible erga omnes en cualquier asunto o procedimiento.

16. Nos centramos en el reconocimiento incidental. Este se produce cuando, en el seno de un procedimiento principal, es necesario resolver sobre la validez de otra resolución dictada en otro Estado miembro. Si bien, el reconocimiento es sencillo ${ }^{8}$, no es automático, pues exige que no concurra ninguno de los motivos de rechazo del reconocimiento que se recogen en el art. $22 .{ }^{9}$ Esto implica que, si

\footnotetext{
${ }^{7}$ A-L Calvo Caravaca-J. Carrascosa Gonzalez," Crisis matrimoniales" Derecho Internacional Privado, vol II, $18^{a}$ edición, Comares, Granada, 2018, pp 297-302

${ }^{8}$ Reglamento 2201/2003 Art 21 :l1. Las resoluciones dictadas en un Estado miembro serán reconocidas en los demás Estados miembros sin necesidad de recurrir a procedimiento alguno. Cuando el reconocimiento de una resolución se plantee de forma incidental ante un órgano jurisdiccional de un Estado miembro, dicho órgano jurisdiccional podrá pronunciarse al respecto.

${ }^{9}$ Reglamento (CE) n ${ }^{\circ}$ 2201/2003 del Consejo, de 27 de noviembre, relativo a la competencia, el reconocimiento y la ejecución de resoluciones en materia matrimonial y de responsabilidad parental Artículo 22 Motivos de denegación del reconocimiento de resoluciones en materia de divorcio, separación judicial o nulidad matrimonial. Las resoluciones en materia de divorcio, separación judicial o nulidad matrimonial no se reconocerán: a) si el reconocimiento fuere manifiestamente contrario al orden público del Estado miembro requerido; b) si, habiéndose dictado en rebeldía del demandado, no se hubiere notificado
} 
no concurre ningún motivo de rechazo, la sentencia dictada en otro Estado miembro producirá efectos de cosa juzgada, considerando lo establecido en la misma como cierto y vinculando al juez del Estado requerido. ${ }^{10}$ No se controla ni la competencia de los tribunales que la dictó ni tampoco la ley aplicada. Precisamente, esa falta de control de la ley aplicable está enfocada a fomentar la libre circulación de resoluciones dentro de la UE. Este Reglamento exige, para el reconocimiento, que se certifique por el tribunal de origen la sentencia objeto de reconocimiento conforme a los dispuesto en el art. $37 \mathrm{y}$ el certificado del art. 39 del Reglamento.

\section{Reconocimiento en materia de responsabilidad parental}

17. El reconocimiento de resoluciones dictadas en materia de responsabilidad parental, dentro de la Unión Europea, se regula también en el Reglamento 2201/2003, funcionando igual que en materia de crisis matrimoniales, es decir, por medio de motivos de rechazo y emisión de certificados. La diferencia estriba en que, en estos casos, los motivos de oposición al reconocimiento se recogen en el art 23, siendo semejantes a los recogidos en el art. 22 pero con las particularidades que exigen los procedimientos con menores implicados, regidos por el principio de interés superior del menor. Para garantizar ese principio, uno de los derechos del menor es el derecho de este a ser oído en función de su edad o grado de madurez. Su vulneración supone un motivo concreto de oposición al reconocimiento, aunque nada indica la resolución que aquí se comenta sobre este aspecto.

18. La parte que se opone al recurso invoca como motivo de rechazo al reconocimiento el art. 22.b) que es el que recoge la Audiencia, pero no se menciona por ningún lado los motivos del art. $23^{11}$, cuando si recoge expresamente en la sentencia que la parte recurrente está solicitando el reconocimiento del pronunciamiento sobre custodia y visitas del padre con los dos hijos menores. No constan datos para mencionar si esta omisión es por desconocimiento, porque no se alegó por la parte o, simplemente, porque en ocasiones, en las resoluciones judiciales no se recoge todo lo que se alega por las partes. No obstante, lo adecuado habría sido que la Audiencia lo hubiera mencionado para una correcta fundamentación jurídica.

\section{Reconocimiento en materia de obligaciones de alimentos}

19. Nos adentramos en el aspecto jurídico clave en el comentario de esta sentencia. Para el estudio de la eficacia extraterritorial de decisiones extranjeras en el ámbito de las obligaciones alimenticias, dentro de la Unión Europea, aplicamos el R 4/2009 que regula dos procedimientos diferentes teniendo en cuenta que se trate de Estados miembros vinculados por el PLH $2007^{12}$ o no. La diferencia esencial entre un sistema y otro es que el primero goza de ciertos privilegios que el segundo no ostenta.

20. El reconocimiento de resoluciones de alimentos dictadas por Estados miembros del R4/2009 vinculadas al Protocolo de la Haya de 2007 se inspira, sustancialmente, en dos principios: reconocimien-

o trasladado al mismo el escrito de demanda o un documento equivalente de forma tal y con la suficiente antelación para que el demandado pueda organizar su defensa, a menos que conste de forma inequívoca que el demandado ha aceptado la resolución; c) si la resolución fuere inconciliable con otra dictada en un litigio entre las mismas partes en el Estado miembro requerido, o bien d) si la resolución fuere inconciliable con otra dictada con anterioridad en otro Estado miembro o en un Estado no miembro en un litigio entre las mismas partes, siempre y cuando la primera resolución reúna las condiciones necesarias para su reconocimiento en el Estado miembro requerido

${ }^{10}$ A-L Calvo Caravaca-J. Carrascosa Gonzalez," Crisis matrimoniales", Derecho Internacional Privado, vol II, $18^{a}$ edición, Comares, Granada, 2018, pp 298

${ }^{11}$ Carecemos de datos para conocer si la parte recurrente invocó el art. $23 \mathrm{c}$ ), que sería el aplicable por coherencia con el citado 22b) que expresamente si menciona la resolución que fue invocado por la parte que recurre y en el que basa el reconocimiento.

${ }^{12}$ Protocolo de la Haya de23 de noviembre de 2007, sobre ley aplicable a las obligaciones alimenticias, ratificado por la Comunidad Europea mediante Decisión del Consejo, de 30 de noviembre de 2009, DOUE-L-2009-82439 
to de pleno derecho sin posibilidad de oposición y la ejecutividad automática de dichas resoluciones, sin necesidad de declaración de ejecutividad en el estado requerido, siempre que estas sean ejecutivas en el Estado de origen ${ }^{13}$.

21. Este Reglamento, con el objetivo de fomentar la libre circulación de resoluciones judiciales en el Espacio Judicial Europeo y especialmente, con la finalidad de facilitar y agilizar el cobro de deudas alimenticias, suprime, con carácter general, la necesidad de un procedimiento de exequátur. El art. 17.1 R 4/2009, establece que, las resoluciones dictadas en un Estado miembro vinculado por el PLH de 2007 serán reconocidas y tendrán fuerza ejecutiva en los demás Estados miembros sin que sea necesario recurrir a proceso alguno y sin posibilidad de impugnar su reconocimiento. "'14 Este precepto puede hacernos pensar, a priori, que el reconocimiento en el Reglamento 4/2009 funciona igual que en el Reglamento 2201/2003, mediante emisión de certificados y la ejecutividad inmediata sin necesidad de procedimiento intermedios, sin embargo, no es así.

22. En efecto, las resoluciones en materia de alimentos dictadas por Estados miembros del R4/2009, vinculados al Protocolo de la Haya de 2007, surtirán efectos en el resto de Los estados miembros sin necesidad de procedimiento de reconocimiento o declaración de ejecutividad, sin posibilidad de impugnar su reconocimiento -aquí la clave de la resolución comentada- y sin necesidad de emitir certificación alguna, siendo esta potestativa y no imperativa. Esto implica que no necesitan ser reconocidas en otros Estados miembros ${ }^{15} \mathrm{y}$, siempre que sean ejecutivas en el Estado miembro de origen, lo serán, automáticamente, en el Estado donde se hace valer, siendo directamente ejecutivas, es decir, que las decisiones extranjeras se pueden hacer valer como un título ejecutivo nacional, sin necesidad de comenzar ningún procedimiento intermedio ${ }^{16}$

23. Cosa diferente es la posibilidad que contempla el Reglamento, en fase de ejecución, a un derecho de reexamen ${ }^{17}$.

24. En el caso que comentamos, al tratarse de una resolución dictada por un tribunal rumano que debe surtir efectos en España y siendo ambos países miembros del Reglamento 4/2009 y vinculados al Protocolo de la Haya de 2007, aunque el esposo en su recurso no mencionara el art. 17.1 del R 4/2009 (datos que desconocemos) a la Audiencia Provincial le debería ser indiferente pues tenía obligación de reconocer de oficio la fuerza ejecutiva de ese pronunciamiento en los términos que se acaban de exponer.

\section{Cosa Juzgada Internacional, ley aplicable y modificaciones de medidas: un "totum revolutum"}

\section{Cosa Juzgada Internacional}

25. Antes de desgranar la desafortunada fundamentación de la Audiencia Provincial de Valencia para denegar el reconocimiento de la pensión de alimentos recogida en la sentencia rumana, no viene

\footnotetext{
${ }^{13}$ M.E CORRAO, "IL diritto internazionale privato e processuale europeo in materia di obbigazioni alimentari"

${ }^{14}$ Esta vía de supresión de exequatur ya fue seguida por el Reglamento (CE) 2201/2003, de 27 de noviembre de 2003, relativo a la competencia, el reconocimiento, y la ejecución de resoluciones judiciales en materia matrimonial y de responsabilidad parental y en el Reglamento 804/2004 de 21 de abril de 2004 por el que se crea un título ejecutivo europeo para créditos no impugnados. La diferencia con estos dos instrumentos internacionales es que el R4/2009 no exige la condición de que sea certificada por el juez de origen. E. CAStellanos Ruiz, Derecho Internacional de Alimentos, Aspectos Internacionales y transfronterizos. Ed. Tirant Lo Blanch,2017.

${ }^{15}$ Sirva de ejemplo: SAP Cádiz, 1 marzo 2016.ECLI:ES:APCA:2016:156.CENDOJ 11012370052016100070

${ }^{16}$ F.PCARI.ViarENGO, "Il Regolamento (CE) no 4/2009 in materia de obbligazioni alimentari” RDIPP, 2009, p.823

${ }^{17}$ El derecho de reexamen se regula en el art 19 y considerando 29 del R 4/2009, únicamente para los supuestos concretos que señala el art. 19, garantizando el derecho de defensa del deudor y se entiende como un recurso extraordinario cuando la resolución se dicta en su ausencia. E. Castellanos Ruz, Derecho Internacional de Alimentos, Aspectos Internacionales y transfronterizos. Ed. Tirant Lo Blanch,2017
} 
mal recordar la normativa que regula la cosa juzgada en nuestra legislación.

26. Encontramos su regulación en nuestro ordenamiento jurídico en los arts. 222 y 416.1.2 $2^{\circ}$ de la LEC. Cuando se invoca esta excepción procesal respecto de una resolución extranjera, es necesario que ésta haya obtenido el reconocimiento en España a través de los mecanismos previstos en Reglamentos europeos, Convenios internacional vigentes en España y en otros instrumentos internacionales vigentes en España o, en su defecto, en la LCJIMC ${ }^{18}$ arts. 44-49. ${ }^{19}$

27. En la sentencia objeto de comentario se estima la excepción de cosa juzgada de la sentencia rumana con relación al pronunciamiento de divorcio y responsabilidad parental de los dos hijos menores. Es correcto. Ambos pronunciamientos han pasado el control del Reglamento 2001/2003 en los términos mencionados anteriormente y superan el reconocimiento incidental. De esta manera despliegan todos sus efectos jurídicos en España como si la hubiera dictado un juez español. Hasta aquí, nada que objetar a la resolución comentada.

28. El dislate de la Audiencia se produce al denegar el reconocimiento de la sentencia rumana relativo al pronunciamiento en materia de alimentos, pues como se ha indicado, es directamente ejecutiva como si la hubiera dictado un juez español. Ahora bien, cuestión distinta es estudiar si el contenido de esa pensión de alimentos se ajusta a la realidad social y nivel de vida existente en España frente a Rumania, país en que se dictó y ver qué mecanismo procesal es el adecuado para adaptarlo y/o modificarlo, si procede.

\section{Modificar medidas sin reconocimiento previo de la resolución objeto de modificación}

29. La argumentación de la Audiencia para denegar el reconocimiento de la pensión de alimentos establecida por la sentencia rumana es un "totum revolutum" de fundamentos jurídicos, sin orden ni concierto. Justifica la denegación del reconocimiento en el Auto del Tribunal Supremo de 17 de septiembre de 2019, relativo a la competencia judicial internacional en una modificación de medidas y justifica que ostenta competencia. Tras justificar su competencia para modificar la medida relativa a la pensión de alimentos, aprovecha esa argumentación para razonar la aplicación de la ley española, pasando por encima de la previa resolución rumana que debiera desplegar plenos efectos jurídicos en España por imperativo del Reglamento 4/2009.

30. Debemos partir de una premisa que se salta la Audiencia: no es posible modificar una resolución extrajera si ésta no ha obtenido previamente el reconocimiento en el Estado en el que pretende ser modificada. Sin ese reconocimiento, de poco sirve estudiar la competencia judicial internacional para modificar medidas en materia de familia ${ }^{20}$. Si no hemos reconocido primero la resolución extranjera que es necesario modificar, sencillamente, no tendremos nada que alterar. La Audiencia se contradice, pues por una parte, deniega el reconocimiento de esa resolución y, por otra, justifica una modificación de la pensión de alimentos de una resolución sin reconocer. Para ello considera que la sentencia española, segunda en el tiempo, es una "modificación" de medidas.

31. El proceso lógico es simple: reconocer la sentencia extranjera según el instrumento internacional aplicable, una vez reconocida, determinar si el tribunal enjuiciador ostenta competencia internacional y territorial y, por último, pero no menos importante, determinar si concurren los requisitos

\footnotetext{
${ }^{18}$ Ley 29/2015, de 30 de julio, de cooperación jurídica internacional en materia civil, BOE n⿳0182 de 31 de Julio de 2015)

${ }^{19}$ A-L Calvo Caravaca-J. Carrascosa Gonzalez, Comentario de la STS 26 noviembre 2015 (5153/2015) www.boe.es/ biblioteca_juridica/comentarios_sentencias_unificacion_doctrina_civil_y_mercantil/abril_pdf.php?id=COM-D-2015-

${ }^{20}$ Sobre la competencia judicial internacional para la modificación de medidas en materia de familia, es muy ilustrativo el comentario al ATS 17 septiembre 2019, de Maria José Valverde Martínez. CDT Vol. 12,, Núm. 1 (2020) https://doi. org/10.20318/cdt.2020.5219
} 
exigidos por la norma interna para justificar si existe variación de circunstancias y si estas han quedado probadas. En este caso hay una realidad incuestionable: la sentencia sobre alimentos dictada en Rumania tiene efectos de cosa juzgada sin necesidad de que el juzgador se pronuncie expresamente. No necesitaba el reconocimiento judicial, ya lo tiene ex lege.

32. Una cuestión debe ser precisada: en materia de obligaciones alimenticias, el Reglamento $4 / 2009$, en su considerando 24 , justifica la fuerza ejecutiva automática de las resoluciones en materia de alimentos sobre la base de las garantías que aporta la aplicación de las normas de conflicto de leyes ${ }^{21}$, siempre que se trate de resoluciones dictadas dentro de su ámbito de aplicación y cuando se trata de Estados miembros vinculados por el PLH 2007. Así, se entiende que al aplicar el Protocolo de la Haya, se garantiza la correcta aplicación de la ley designada por la norma de conflicto, lo que supone una revitalización de la función garante de esta ${ }^{22}$. Esta afirmación implica que la ley aplicable que fundamenta la sentencia reconocida no puede ser controlada por el juez español, lo que obedece al fomento de la libertad de circulación de resoluciones europeas y, en materia deee111e alimentos, además, sirve para incrementar las garantías de cobro. La única excepción la encontramos en que el pronunciamiento que se pretende reconocer o ejecutar fuese contrario al orden público internacional español, lo que no sucede en este caso.

\section{Conclusión}

33. Con base en los hechos y datos recogidos en la sentencia objeto de comentario, la solución del objeto del litigio no presenta mayor complejidad que el pleno conocimiento de los Reglamentos europeos integrados con la norma interna del tribunal que enjuicia.

34. No todos los Reglamentos en materia de reconocimiento y ejecución funcionan igual, como se ha explicado. Partiendo de este hecho, la correcta solución del caso debía pasar por el reconocimiento total de la sentencia dictada por el tribunal de Botosaní, al haber sido dictada con carácter previo a la española y coincidiendo las mismas partes, objeto y causa. Dicha resolución goza en el ordenamiento jurídico español de efectos de cosa juzgada, pero el reconocimiento en materia de alimentos es automático mientras que el del divorcio y medidas de custodia y visitas permiten oponer motivos de rechazo, aunque en este caso procedía su denegación.

35. Cuestión diferente es, si una vez reconocida la sentencia rumana en su totalidad, procede ajustar o modificar el importe de la pensión de alimentos fijado en Rumania a la realidad española. No cabe duda de que la solución dada por la Audiencia se dicta buscando el interés de los menores, no obstante, en su exceso de celo protector del menor, olvida o desconoce que las normas europeas están por encima de las nacionales.

36. En efecto, las resoluciones extranjeras que han sido reconocidas en España despliegan eficacia de cosa juzgada, sin embargo, en derecho de familia, estas pueden ser modificadas si concurren circunstancias que alteren de forma relevante la decisión tomada según las circunstancias concretas del caso en el momento de tomarse esa decisión. Desconocemos los datos del caso concreto, más allá de la escasa diferencia de dos meses en que fueron dictadas una y otra resolución, por lo que no podemos valorar si la decisión de adaptar la pensión de alimentos a la realidad española pudo ser acertada en beneficio de los menores, a pesar de la incorrecta fundamentación jurídica.

\footnotetext{
${ }^{21}$ Con relación a las normas de conflicto contenidas en los Reglamentos europeos, estas son imperativamente aplicables en todos los Estados miembros por disposición del art. 288.II TFUE y, en nuestro ordenamiento jurídico interno, por imperativo del art. 12.6 CC.

${ }^{22}$ Marina Vargas Urrutia, El cobro internacional de alimentos. Reflejos del dispositivo protector del acreedor de alimentos en las normas del Reglamento 4/2009. Revista de Derecho de la Unión Europea, Madrid ISSN 1695-1085 m²2-enero-junio, pág. 99-118
} 
37. Lo que no se puede negar es que la Audiencia Provincial no analiza realmente una modificación de medidas, sino que "impone" el fallo de la sentencia española sin tener en cuenta la plena validez de la sentencia rumana, vulnerando el derecho a la libre circulación de resoluciones europeas.

38. Como conclusión, se puede extraer una realidad práctica: En materia de familia, los reglamentos europeos ya están presentes en casi todos los juzgados y tribunales españoles, sin embargo, todavía no se conoce con detalle técnico suficiente el funcionamiento de estos complejos instrumentos, dando lugar a resoluciones incompletas, incorrectas o poco precisas que generan inseguridad jurídica en operadores jurídicos y justiciables. 